\title{
Rebuilding Evolution: A Service Science Perspective
}

\author{
Jim Spohrer \\ IBM Research \\ spohrer@us.ibm.com
}

\author{
Md Abul Kalam Siddike \\ Japan Advanced Institute of \\ Science and Technology \\ kalam.siddike@gmail.com
}

\author{
Youji Kohda \\ Japan Advanced Institute of \\ Science and Technology \\ kohda@jaist.ac.jp
}

\begin{abstract}
This paper explores a simple idea and asks a simple question: What determines the speed limit of evolutionary processes, and might there be ways to speed up those processes for certain types of systems under certain conditions? Or even more simply, how rapidly can complex systems be rebuilt? To begin with, the universe can be viewed as an evolving ecology of entities. Entities correspond to types of systems - from atoms in stars to organisms on Earth to ideas in the heads of people. Service science is the study of the evolving ecology of service system entities, complex socio-technical systems with rights and responsibilities - such as people, businesses, and nations. We can only scratch the surface in this paper, but our explorations suggest this is an important research question and direction, especially as we enter the cognitive era of smart and wise service systems. For example, it takes a child multiple years of experience to learn language and basic social interactions skills, but could machine learning algorithms with the proper data sets learn those capabilities in a fraction of the time?
\end{abstract}

\section{Introduction}

Is the rate of innovation speeding up in service systems [1-2]? For example, the time it takes to reach a million users of certain innovative technologies has decreased substantially in the last two centuries (automobiles took multiple decades to reach a million customers/users, while social media adoption has taken mere months in some cases). However, in general, what can be said about speed limits of change and evolution? How fast can organizational complexity arise from evolutionary processes in biological systems? How fast can ecological diversity arise from evolutionary processes? Earth formed some 4.5 billions years ago, and within a billion years, primitive bacteria had already established themselves.

Does evolution have a speed limit? In biology, Darwin's [3] theory of evolution proposed the mechanism of natural selection to explain the way that essentially random processes could give rise to the diversity and complexity of species. Kaufman [4] proposed autocatalysis as an additional mechanism to explain the chemical foundations of certain biological processes in networks that underlie the complexity and diversity of biological species. Mechanisms such as these are part of the explanation for how complex structures arise-mechanisms and structures coevolve. Basically, Darwinian evolution alone, by trying random combinations and having competition for viability, is too slow a mechanism to fully explain how rapidly multiscale complex structures emerged in life on Earth. Kauffman shows that networks can form under the right conditions, and some of these networks that are at the edge of chaos (dynamically balanced between order-stability and disorder-chaos) may become viable more rapidly because of emergent properties at a next higher level of organizational scale. In essence, higher level emergent properties feedback down and bias the likelihood of outcomes in lower level networks.

Beyond biology and chemistry, what about others types of systems that evolve - are there different speed limits? Boulding [5], in a short essay entitled 'General Systems Theory-The Skeleton of Science’, suggests two possible approaches to organize general systems theory.......at least two roads each of which is worth exploring. The first is to identify general phenomena, such as population, individual, growth and information and communications, which might be called an ecological approach (a general field theory of dynamics of action and interactions). The second is to arrange... a hierarchy of complexity of organization, such as statics, dynamics, control, self-maintenance, genetic-societal, teleological, symbolic-communication (with self-awareness and the ability to know what one knows), social-value and transcendental systems, which might be called an evolutionary approach (system of systems...each level incorporates all of those below it). As Boulding points out, these two approaches (general phenomena/ecological and ordered complexity/evolutionary) are complementary rather than competitive approaches. 
People and their ideas are an interesting physicalsymbol system, since both biological and nonbiological processes are at work, driving change in the system. Human evolution is driven by adaptation of people to their environment, and that environment includes both physical and symbolic resources [6]. Simon [7] further developed the notion of hierarchical complexity in his work on 'sciences of the artificial'. Arthur [8] more recently developed a further theory of the nature of technology as ever more complex recombination of prior technologies, and Auerswald [9] talks about 'production recipes' in economics as recombination of prior recipes including both technologies and rules, as ingredients that can be combined to form new, more complex technologies and rules. However, perhaps the most profound elaboration of combined ecological and evolutionary approaches can be found in Deacon [10], a work which carefully builds from thermodynamics to life to consciousness to societal systems, step by step with all the rigour of a philosopher's logical toolkit. Spohrer et al. [2] provide a far less rigorous but nevertheless useful broad brush perspective of the same territory by using a combined ecological and evolutionary view of physical systems, chemical systems, biological systems and service systems.

The motivation for this paper lies in the observation that Darwinian evolution alone is too slow (to explain the world) and Kauffman evolution, while faster is perhaps still too slow to explain the rate of change in complex, dynamic, evolving systems. Aside from running Monte Carlo simulations of complex systems, is it possible to say more about the speed limits of change and evolution in different types of systems? Perhaps, and in this paper, we will discuss the evolution of multiple types of systems from a service science perspective, looking for clues about the nature of speed limits in evolving systems with populations of entities and interactions.

\section{Individuals to Systems}

\subsection{Natural Systems}

Almost 14 billion years ago, our universe started with a 'big bang'. And through a process known as fusion, stars turned populations of lighter atoms like hydrogen into heavier atoms like helium, and when stars of a certain size have done all the fusion they could, they would start slowing down, and eventually collapse rapidly, go nova, explode and send heavier atoms out into the universe, and eventually new stars form, and the process repeats over and over, including heavier and heavier elements. Eventually, after about five billion years, a very important star formed - our Sun. From large quantities of iron, nickel, and other atoms the Earth formed about 4.3 Billion years ago. In less than a billion years, the early Earth evolved a remarkable ecology of complex molecules, including amino acids, and after less than a billion years, an ecology of bacteria took hold on early Earth.

The ecology of single cell bacteria flourished and after another million years of interactions between the bacteria, the first multi cellular organisms formed, and soon the ecology of sponges and other multi-cellular entities began to spread out across the earth. Then after nearly two billion years, a type of division of labor between the cells in multi cellular organism lead to entities with cells acting as neurons in the first clams, and these neurons allowed the clams to open and close at the right time. After only 200 million years, trilobites appeared the first organisms with dense neural structures that could be called brains appeared, and then after about 300 million years, multi-cellular organisms as complex as bees appeared, and these were social insects, with division of labor among individuals in population, with queens, drones, worker bees. So 200 million years ago, over 14.5 billion years after the big bang, the ecology of living entities is well established on planet Earth, including social entities with brain and division of labor between individuals in a population.

\subsection{Cognitive Systems}

Now we are at the dawn of a much bigger shift in the evolution of technology-a new era affecting nearly every aspect of the field. The changes that are coming over the next two decades will transform the way we live and work just as the computing revolution has transformed the human landscape over the past half century.... call this the era of cognitive computing. -John E. Kelly III

The term 'Cognitive computing' was introduced by John E Kelly III and Steve Hamm [11] to general audiences and provide a window into the future of computing. Cognitive computing will ultimately be able to interpret images, numbers, voices, and sensory information. It will participate dialogue with human beings aimed at navigating vast quantities of information to solve extremely complicated yet common problems. The goal is to transform the way human get things done, from health care and education to financial services and government. In the era of cognitive systems, humans and machine will collaborate to produce better results, each bring their own superior skills to the partnership. The machine 
will be more rational and analytic - and, of course, possess encyclopedic memories and tremendous computational abilities. People will provide expertise, judgement, intuition, empathy, a moral compass, and human creativity [11]. In this era of cognitive systems, humans and machine will become more interconnected. Furthermore, cognitive systems can provide customers with high-quality recommendations and help customers make better data-driven decisions [12].

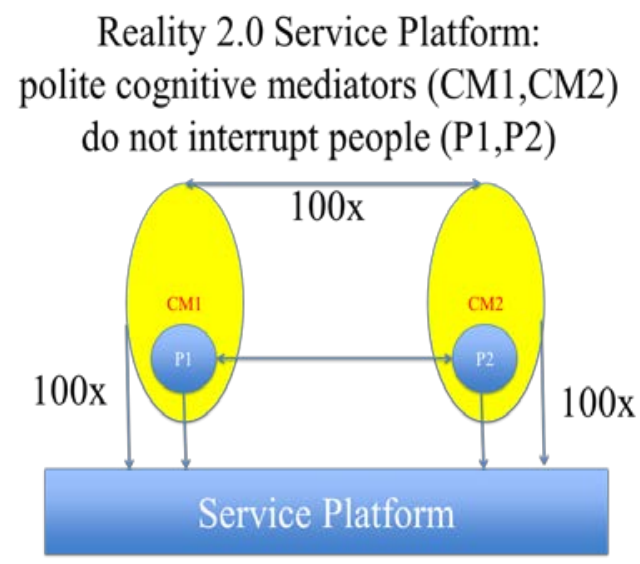

Figure 1: Reality 2.0 in Cognitive Service Systems [13]

In the era of cognitive systems, human problem solving capabilities significantly augmented by the interaction of humans and machine. Engineers predict that by 2035, nearly every one of the human ecology has a cognitive mediator that knows them in many ways better than they know themselves. Furthermore, engineers predict that by 2055, nearly everyone has 100 cognitive assistants that "work for them" [14] (See Figure 1). As a result, entities of the interconnected, nested and networked ecology boost both creativity and productivity by cognitive mediators with deep knowledge of both customers (users) and providers (experts) as co-creation of win-win value. In this way, all entities (people, organizations and society) use cognitive mediators to enhance value co-creation interactions. Almost all the people including doctors, physicians, patients, bankers, policymakers, tourists, customers, as well as community people greatly augmented their capabilities by the cognitive mediators or cognition as a service [15].

In the cognitive systems, the volume of data creates the potential for people to understand the environment around us with a depth and clarity that was simply not possible before using computational power. In the era of cognitive computing, using the new tools of decision science, humans will be able to apply new kinds of computing power to huge amounts of data and achieve deeper insight into how things really work. In this age, humans think big data as a natural resource waiting to be mind. And in order to tap this vast resource, humans need computers that "think" and interact more like humans do [11]. In this case, cognitive systems will learn, adapt and interact with humans for augmenting human capabilities to take better decision for solving complex problems in human life. Cognition-as-aService (CaaS), provided for instance in the cloud and on mobile devices, aims to augment and scale the performance of people through the use of cognitive assistants. CaaS creates opportunities for service providers to augment the capabilities of employees, customers, and other ecosystem partners; for example, applications of IBM's Watson Services on Bluemix (one implementation of CaaS) can be used in the context of healthcare to assist doctors, nurses, and other caregivers, patients and their families, as well as insurance providers, local pharmacies, and other ecosystem partners [15].

Cognitive systems can potentially progress from tools to assistants to collaborators to coaches, and be perceived differently depending on the role service system entities play in a service system. In this case, cognitive systems acquire better and better models of their users and more expert cognitive and social capabilities [14]. Forbus [16] articulated that AI achieved social organisms through apprentice providing some form of works, with roles and responsibilities allowing $\mathrm{AI}$ entering into human culture. In this case, apprenticeship will allow AI to achieve some roles and responsibilities of human culture. Furthermore, Lenat [17] predict the future of AI providing "weak telepathy" (AI understands what you have in mind and why, and completes that action), "weak immortality" (even after your death, it can continue to interact with loved ones, friends, business associates, carry on conversations, carry our assigned tasks and others), and "weak cloning" (refers to the science fiction type of duplication of you instantly as you are now, able to be in several places at once). Finally, Spohrer [14] predicted that with the help of a cognitive assistant, a young adult in 2055, could have the ability and the experience to rapidly rebuild societal infrastructure from the scratch.

\subsection{Service Systems}

From a service science perspective, progress can be thought of in terms of the rights and responsibilities of entities (individuals and institutions). Entities that can trust each other can more efficiently play complex nonzero-sum games. In our human service ecology, value-cocreation depends on trust, and trust depends on rights and responsibilities. Rights are associated with societal benefits and freedoms, and responsibilities are 
associated with societal constraints (backed up by the threat of loss of rights or access to resources as well as reputation damage, fines or coercion). In this age of big data, social media and sensors proliferation, Spohrer et al. [18] imagined four 'parallel time streams' associated with (1) phenomena (sources of information); (2) research (knowledge creation); (3) education (knowledge transfer); and (4) practice (knowledge application). Practice could be further broken down into commercial practice (e.g. technology) and governance practice (e.g. rules). As a symbolic species, humans create new symbols at particular points in time, and these symbols are part of scientific theories that provide insights into the origins of abstract entities, interaction and outcome universals [19].

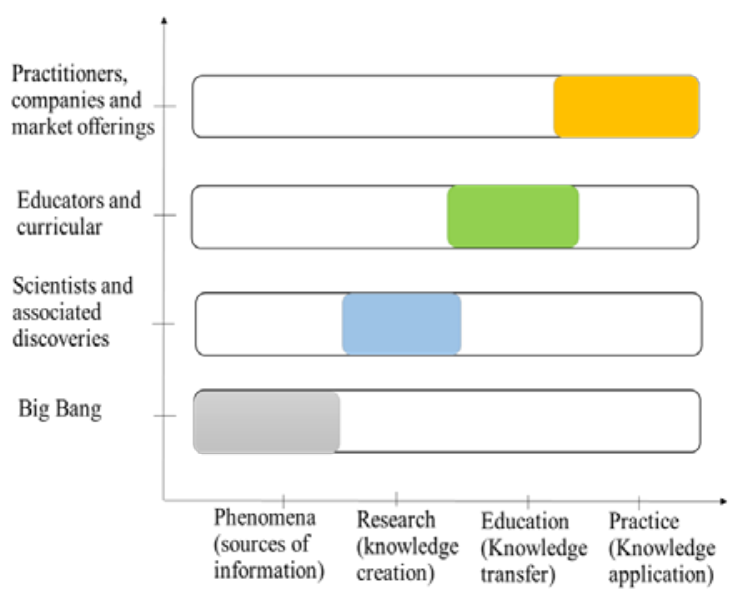

Figure 2: Progress in service science

The first stream is the 'phenomena stream', which begins with the symbol 'Big Bang' and date of approximately 14 billion years ago. The second stream is the 'research stream', which includes the symbols referring to the names of scientists and their associated discoveries (such as the Hubble, 1924-1949, Big Bang) and the year (or range) in which an individual (or cohort) developed the conceptual framework and put names (that stuck or faded) to discoveries in published or public forums. The third stream is the 'education stream', which might include the symbols referring to the names of educators and their curriculum and the year in which they first began teaching about those topics. The fourth stream is the 'practice stream', which might include the symbols referring to the names of practitioners, their companies and their market offerings and the year in which they began creating economic value embodying certain knowledge in certain offerings. For example, the first advertisements for the Intel 4004 microprocessor appeared on 15 November 1971 in Electronics News.

The fourth stream also includes symbols associated with new formal entities and rules. Formal service system entities have rights and responsibilities that can be described and debated in terms of formal symbol systems. As a symbolic species [20], we humans can be viewed as service systems entities (Spohrer and Maglio, 2010) or in Simon's terminology, physical symbol systems [22] [7]. Therefore, evolution of new types of service system entities is in part a legal process of naming and specifying rights and responsibilities, and in any nation or jurisdiction, it is possible to determine when those formal entities were created, for example, the birth of the nation the USA in 1776, and it was in 1886 (Santa Clara County versus Southern Pacific Railroad) that US corporations won many of the rights to be treated as legal citizens [23]. Of course, our path-dependent service ecology was evolving new types of service system entities well before rule of law in the formal, symbolic sense, and the transition from primate to human and early human to formal, written law is well documented in the literature, including the study of Friedman [24]. Simplifying all human knowledge to symbolic knowledge is a great oversimplification ignoring other forms of knowledge in tacit patterns and configurations, but doing so allows a systematic approach to the knowledge burden that can approach the speed limit of what is possible regarding the rate of progress.

Given that the path-dependent history of symbolic knowledge (our growing knowledge burden) can be viewed in terms of four interconnected streams: phenomena, research, education and practice (both commerce/entrepreneurship and governance/ policymaker), universities as home to diverse academic disciplines play a special role in human society. Each discipline has further subspecialists who focus on knowledge creation (research), knowledge transfer (teaching) and knowledge application (commerce/ entrepreneurship and governance/policymaker). Universities today can be seen as 'knowledge factories' with disciplines springing up to study phenomena associated with certain segments of the empirical world, as noted by Boulding [5]. Universities have been described in terms of three knowledge-related activity streams or themes: create knowledge (research), transfer knowledge (education) and apply knowledge to create value (practice). Mollas-Gallart et al. [25] report that although most universities were founded principally on two activities, teaching and research, they have always made wider contributions to civil society through their 'third mission' activities, an d now more than ever, universities are the 'dynamos of growth’ for their regions in a knowledge-driven global 
economy. In fact, measuring the regional economic impact of universities and ranking universities in terms of start-up activities is becoming more and more important [26]. Of course, knowledge can be applied in many other arenas besides commerce, for example, policymakers creating new rules and rule systems to improve governance. For example, practice includes engineers developing new technologies (such as the microprocessor) and can also include leaders in management (total quality movement), leaders in government (emancipation proclamation) or civic leaders (women's right to vote). Observers of higher educational change expect more change in the next few decades than in the previous thousand years [27]. New technology and new business models are beginning to disrupt the lecture-mode of knowledge transfer that has characterized higher education for a thousand years [28]. As a result, faculty labour in higher education is shifting more and more from the dominant first stream activities (transfer of knowledge-teaching) to rapidly growing third stream activities (applying knowledge to create value-entrepreneurship), which is, in turn, driven by accelerating second stream activities (create knowledge_research).

Through the institution of the university, most disciplines reward knowledge depth, not breadth. However, future universities, without sacrificing knowledge depth, may be quite different. Reframed as test bed living labs that embrace general systems theory, universities could better prepare students as 'global citizens and adaptive innovators' with both depth and breadth, so-called-shaped professionals [2931]. At the least, a multidisciplinary research perspective is required to develop the strategies, processes, training pedagogy and toolsets for lean engagement models that reduce integration overhead and that concomitantly prepare the next generation of service specialists (e.g. T-shaped professionals) who possess highly evolved integration skills [32]. Furthermore, this reframing of universities might better balance the benefits and drawbacks of winner-take-all and improve-weakest-link policy logics while continuously improving the recapitulations of recorded 'phenomena, research, education and practice' that advance quality-of life levels [33]. The university in modern society is a type of essential institution that can be seen in terms of four intertwined and coevolving threads, namely the threads of phenomena, research, education and practice. Universities may already be leading a global societal transformation to balance the dominant zero-sum 'winner-take-all' competitive logic with doses of nonzero-sum 'improve-weakest-link' cooperative logic, resulting in an overall service dominant or value-cocreation logic accelerating societal progress.
Progress that begins with an appreciation of the knowledge burden of a service ecology. If the lifespan of entities does not allow for the transfer of knowledge from one generation to the next, then problems and opportunities arise for progress. New ideas (knowledge) that can be applied to increase the lifespan of entities, increase the efficiency of knowledge transfer between entities, decrease the amount of knowledge that needs to be transmitted by and to entities, etc. can impact the knowledge burden of a service ecology. New types of entities or reinventing existing entities (institutions) with new capabilities can also impact the knowledge burden of a service ecology.

\subsection{Smart Service Systems}

Service system is the configuration of people, technology, organization and information that are designed to interact through value proposition and cocreate mutual value [34-35]. Smart service systems are then based upon interactions, and may be represented by intelligent utility network and metering, intelligent transportation, consumer driven supply chains, intelligent oilfields, and manufacturing productivity, etc. In this light interactions, ties and experiences among actors represent an important part of smart service systems (Barile and Polese, 2010).

Recently, National Science Foundation popularized the term "smart service system". According to National Science Foundation [36], a smart service system is a system capable of learning, dynamic adaptation, and decision making based upon data received, transmitted, and/or processed to improve its response to a future situation. The system does so through self-detection, self-diagnosing, self-correcting, self-monitoring, selforganizing, self-replicating, or self-controlled functions. These capabilities are the result of the incorporation of technologies for sensing, actuation, coordination, communication, control, etc. The system may exhibit a sequence of features such as detection, classification, and localization that lead to an outcome occurring within a reasonable time. The resulting system requires an understanding of human interaction with technology and a human-centered design to assure the desirability and the effectiveness of the proposed service system" (p. 5).

Significant advances in, and adaptations of, sensing, actuating, and computational and communication technologies and their integration into smart service systems have the potential for abundant societal and economic benefits [37]. Human interaction with technologies and with physical and virtual realities can produce and deliver service(s) never before imagined [36]. The characteristics of smart service system is 
"first and foremost, a smart service system that is human-centered. A human-centered service system involves users, recipients, beneficiaries, providers, and/or decision makers utilizing the information and capability provided by the service. Second, interactions between humans and physical/virtual realities necessarily happen and are integral to the "service". Sometimes, these interactions happen in different sequences and combinations, in parallel or series, among physical and virtual worlds before interacting with the human reality. Sometimes, interactions occur with the human world from the start, but interactions always occur. These interfaces with humans can take many forms: e.g., co-creation, interaction, response, needs assessment, surveillance, etc. Third, the interactions need to add value to humans; for an activity to become a service, a human or group of humans need to ultimately benefit from the interactions either directly or indirectly" (p. 5).

Furthermore, Smart service systems can be characterized by: (1) the types of offerings to their customers and/or citizens, (2) the types of jobs or roles for people within them, and (3) the types of returns they offer investors interested in growth and development, through improved use of technology, talent, or organizational and governance forms, which create (dis) incentives that (re) shape behaviors. In part, because of analytics and cognitive systems, smart service systems adapt to a constantly changing environment to benefit customers and providers. Using big data analytics, service providers try to compete for customers by (1) improving existing offerings to customers, (2) innovating new types of offerings, (3) evolving their portfolio of offerings and making better recommendations to customers, (4) changing their relationships to suppliers and others in the ecosystem in ways their customers perceive as more sustainable, fair, or responsible [38]. In the same way, MedinaBorja [39] mentioned that smart service systems span across a variety of socio-technical facets comprising of devices, people, organizations, environments and technologies to sense, actuate, control and assess the physical, cyber and societal artifacts of the human service systems. Besides being self-adaptive and faulttolerant, such systems need to be designed in such a way that they can continuously increase the quality and productivity, as well as the compliance and sustainability of the smart services it offers. Understanding the societal and economic impact and human-centered aspects of a smart system or technology in advance and designing the system apriori with potential value-added services can help to spur the discoveries of new tools, methodologies and innovative services. Calza et al. [40] considered service systems as value-co-creation and "Smart" if they are supported by IT and react to external changes for the satisfaction of the whole. The co-production of value occurs by processes coordinating the participants, which exchange services, and including decisionmaking activities, such as the choice of a specific service provider.

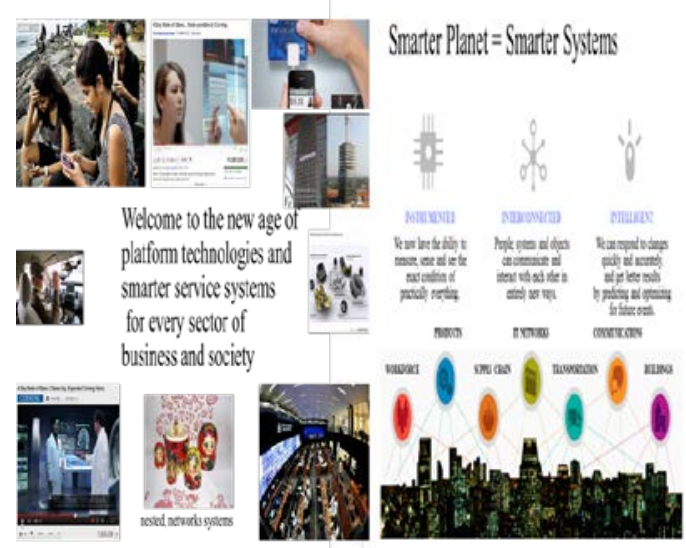

Figure 3: Smart Systems and smart planet [12]

Demirkan et al. [12] explained how big data and analytics are related to smart services and smart planet (Figure 3). According to them, because business and societal systems are instrumented (sensors), interconnected (data stored in the cloud and accessible from mobile devices), and intelligent (cognitive systems can provide customers with high-quality recommendations and help customers make better data-driven decisions), we can say that business and societal systems are getting smarter. Across all sectors, systems - transportation, water, food, manufacturing, energy, communications, retail \& hospitality, finance, healthcare, education, and even government systemsare becoming smarter. In addition, of course, we would expect smarter systems to waste fewer scarce resources and lead to more productive and sustainable systems. Many types of smarter service depend on IT as a service, including big data analytics. From rerouting traffic around congestion to personalized medicine avoiding drug interactions, smart service depends on better data and better models of value realization. Scare or uncertain data and outdated or inappropriate models of customer value realization can be problematic. Accurate measurements of a dynamic world and accurate knowledge about a dynamic customer are needed to provide smart service.

In the age of smart technologies such as IBM Watson and Apple Siri, service system requires systematic exploration of resource configuration to improve existing offerings, create new offerings, or reconfigure ecosystem partners [41]. In a nutshell, 
capturing and using data and technology in service systems to create smart service systems requires sensing human behavior, analyzing data to develop models of human behavior or models of human skill, and applying the models to support or automate the actions of service systems. Service depends on people, human behavior, human cognition, human emotions, and human needs. Service systems are getting larger and larger, incorporating global enterprises, global industries, and world governments. Data is getting bigger and bigger, capturing both human actions and economic transactions on an almost unimaginable scale. Technology (and computational technology in particular) is getting more and more powerful, for instance, enabling the effective use of data to support and automate service interactions and service operations. In the end, service is about people working together and with technology to create mutual value [42].

\subsection{Wise Service systems}

The idea of "wisdom computing” was came up by Japan Science and Technology Agency (JST) and several researchers [43-47]. Wisdom computing is concerned with the design, management, use, and implications of information technologies for discovering, creating, sharing, and supporting wisdom [43]. Wisdom computing makes intelligent world richer and lead humans to better decision under complicate and ever changing situations. It makes human life better in quality and humans gain abilities to deal with machines whose ever-increasing capabilities threaten human works and intelligence [44]. Wisdom computing focuses on interactions between humans and machines for accumulation, propagation and exploration of wisdom. In this era of overwhelming information explosion, humans are capable of accessing widespread "infinite" information in real time, but humans cannot claim that we have become wiser than ever individually and collectively. On the other hand, machines and computers are attaining enormous capabilities in accessing and analyzing information and controlling objects such as airplanes and automobiles [46]. Research activities in Japan related to "wise computing" focuses on understand and develop wisdom by sublimating distributed and heterogeneous data and information. Wisdom will be accomplished through collaboration between people and machines and aims to devise a way to influence the real world with wise decisions by applying achieved wisdom [45]. It also focuses on ethical, legal, and social issues related to social responsibilities for actuation of wisdom [46].
Spohrer, Bassano, Piciocchi and Siddike [48] proposed wise service system based on intelligence and multi-generational human values in the context of rigorous and formal examples of engineering changes to sociotechnical systems. Intelligence involves language, learning, and levels of confidence in cognitive systems [15]. On the other hand, wisdom connects with human values and stands the test of time and perspectives of multiple generations; wisdom connects to courage and not cowardice; wisdom does not control the narrative cosmetically or politically, but does suggest a higher purpose for our actions than individual selfishness or complete altruism [48]. Bostrom in his book "Superintelligence" writes about ethical artificial intelligences, and highlights the work of American artificial intelligence researcher Eliezer Yudkowsky, who writes about coherent extrapolated volition (CEV), timeless decision theory, and the complex value systems that may well be required to realize valuable futures [49-50].

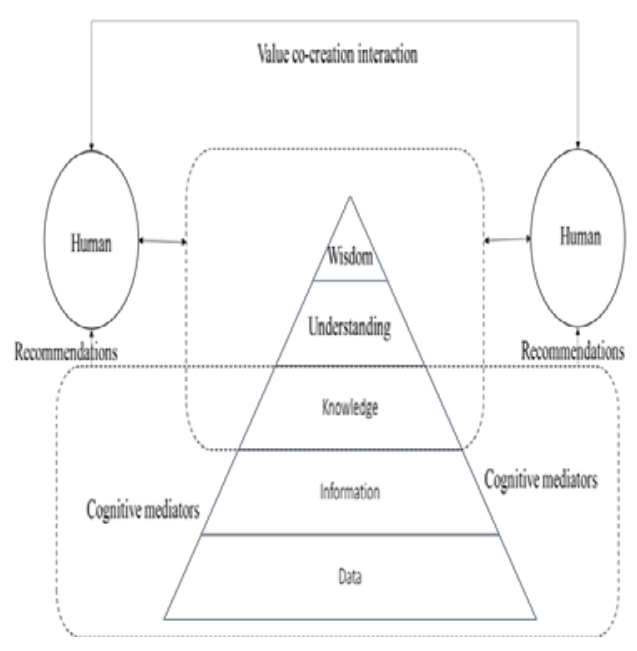

Figure 4: Wise service systems

In the area of cognitive computing, almost all the people of our society including doctors, physicians, patients, bankers, policymakers, tourists, customers, as well as community people greatly augmented by the cognitive mediators [14]. However, beyond cognitive computing, wise computing deals with issues relating to legal, ethical, public policy. Cognitive systems will allow cognitive assistants for all occupations in smart service systems, boosting people's creativity and productivity. Wise systems improve sustainability and justice [47]. In this paper, we defined wise service system as socio-technical systems in which the cognitive mediators interact with people to augment human capabilities through providing precise recommendations by actuating the context and 
situation that help them to take right decisions to solve complex problems more efficiently and perfectly. A wise service system will help our next generation to build and re-build from the scratch. In the wise service system, cognitive mediators provide recommendations to human and human use the recommendations based on their experiences, knowledge and skills to solve complex problems. Through this way, human and machine will collaborate harmoniously and generate win-win value co-creation for the human (See Figure 4).

Nevertheless, the way people resolve conflicts, from science to business to politics, and the healthy competition of ideas is at the heart of exploring, risk taking, and learning. Coherence that comes from adopting cultural or methodological blinders may well represent emotional and cognitive biases to be avoided - when appropriate, breaking the chains of traditional thinking is an important responsibility of wise leaders concerned with sustainable innovation [50]. Competition can be an important mechanism for value co-creation and capability co-elevation of entities in a healthy, diverse ecology of service system entities [51]. Engineering rigor, should not lead to rigor mortis - that would be unwise. In sum, all sociotechnical systems are learning systems that must explicitly or implicitly decide to invest resources in routine activities (exploitation) or new activities (exploration) [52]. For individuals the investment has been studied, and related to growth of capabilities over time [53-54]. For sociotechnical systems in general, understanding if there are smart and wise "speed limits" or "no speed limits” for the growth of sociotechnical system capabilities is an open question [18] [55]. These are issues for the human-side of service engineering to study in the context of increasing customer capabilities through improved value co-creation interactions [56].

\section{Conclusions and Future Research}

We can summarize the sections above as follows (See Table 1). This paper has begun to explore a simple idea and asks a simple question: What determines the speed limit of evolutionary processes, and might there be ways to speed up those processes for certain types of systems under certain conditions? Or even more simply, how rapidly can complex systems be rebuilt? We have only scratched the surface in this paper, but our explorations suggest this is an important research question and direction, especially as we enter the cognitive era of smart and wise service systems. Service science is the study of the evolving ecology of service system entities, complex sociotechnical systems with rights and responsibilities such as people, businesses, and nations. As the building blocks get better, we are able to imagine (re)building things that would have taken nations in earlier years to accomplish (putting a satellite in orbit) as a high school science project for a small team of students. Or machine learning algorithms and data sets that allow simulated cognitive entities to learn simple languages and social interactions skills in a fraction of the time required for these skills in human evolution.

Table 1: Types of systems and emergent ecologies of entities

\begin{tabular}{|l|l|}
\hline $\begin{array}{l}\text { Types of } \\
\text { systems }\end{array}$ & Emergent ecologies of entities \\
\hline $\begin{array}{l}\text { Natural } \\
\text { systems }\end{array}$ & $\begin{array}{l}\text { Emergence of atoms (stars), } \\
\text { molecules (planets), life } \\
\text { (biosphere/ecology) }\end{array}$ \\
\hline $\begin{array}{l}\text { Cognitive } \\
\text { systems }\end{array}$ & $\begin{array}{l}\text { Emergence of intelligence, tacit } \\
\text { knowledge (rapid learning) in } \\
\text { people }\end{array}$ \\
\hline $\begin{array}{l}\text { Service } \\
\text { systems }\end{array}$ & $\begin{array}{l}\text { Emergence of rights and } \\
\text { responsibilities (institutions) }\end{array}$ \\
\hline $\begin{array}{l}\text { Smart } \\
\text { service } \\
\text { systems }\end{array}$ & $\begin{array}{l}\text { Emergence of smart technologies } \\
\text { and better rules/governance to } \\
\text { avoid waste }\end{array}$ \\
\hline $\begin{array}{l}\text { Wise service } \\
\text { systems }\end{array}$ & $\begin{array}{l}\text { Emergence of multi-generational } \\
\text { human values (smart across } \\
\text { generations) }\end{array}$ \\
\hline
\end{tabular}

A future research direction is to begin to make the rough ideas sketched in this paper more quantitative. For example, people provide an existence proof for the amount time, data, and processing to learn language. How can we begin to reframe the idea of rebuilding evolution in a more quantitative manner?

\section{References}

[1] J. Spohrer, Service science, In leadership in science and technology: A reference handbook, W. S. Bainbridge (ed.), W.S. Sage Publications, New York City, NY, 2011.

[2] J.C. Spohrer, H. Demirkan and V. Krishna, Service and science, In The Science of Service Systems, H. Demirkan, J.C. Spohrer and V. Krishna (eds.), Springer Publishing, New York City, NY, 2011.

[3] C. Darwin, The origin of species, John Murray, London, 1872.

[4] S. Kauffman, At home in the universe: the search for laws of self-organization and complexity, Oxford University Press, New York NY, 1995.

[5] K.E. Boulding, "General systems theory - the skeleton of science”, Management Science, vol. 2, no. 3, 1956, pp. 197208.

[6] J.C. Spohrer and D.C. Engelbart, "Converging technologies for enhancing human performance”, Annals of the New York Academy of Sciences, vol. 1013, 2004, pp. 5080. 
[7] H.A. Simon, The sciences of the artificial, The MIT Press, Cambridge Mass, 1996.

[8] W.B. Arthur, The nature of technology: what it is and how it evolves, Free Press, New York NY, 2009.

[9] P.E. Auerswald, The coming prosperity: how entrepreneurs are transforming the global economy, Oxford University Press, Oxford, UK, 2012.

[10] T.W. Deacon, Incomplete nature: how mind emerged from matter, Norton \& Company, New York, NY, 2013.

[11] J.E. Kelly III and S. Hamm, Smart machines: IBM's Watson and the era of cognitive computing, Columbia University Press, New York, USA, 2013.

[12] H. Demirkan, C. Bess, J. Spohrer, A. Rayes, D. Allen and Y. Moghaddam, "Innovation with smart service sytems: analytics, big data, cognitive assistance and the internet of everything, Communications of the Association for Information Systems, vol. 37, 2015, pp. 733-752.

[13] J. Spohrer, Keynote: engineering grand challenges \& solving them (with a little from the future: our very polite cognitive mediators), Engineers for a Sustainable World: Design-Educate-Build, Berkeley, CA, USA. Friday April 8, 2016. Available at: http://www.slideshare.net/spohrer/ spohrer-esw-20160408-v4.

[14] J. Spohrer, Innovation for jobs with cognitive assistants: a service science perspective, In Disrupting Unemployment (Ed. Nordfors, Cerf and Senges), Ewing Marion Kauffman Foundation, Missouri, USA, 2016, pp. 157-174.

[15] J. Spohrer and G. Banavar, "Cognition as a service: an industry perspective”, AI Magazine, vol. 36, no. 4, 2015, pp. 71-86.

[16] K. D. Forbus, "Software social organisms: implications for measuring AI progress, AI Magazine, vol. 37, no. 1, 2016, pp. 85-90.

[17] D.B. Lenat, "WWTS (what would Turing say?)”, $A I$ Magazine, vol. 37, no. 1, 2016, pp. 97-101.

[18] J. Spohrer, A. Giuiusa, H. Demirkan and D. Ing, "Service science: reframing progress with universities", Systems Research and Behavioral Science, vol. 30, no. 5, 2013, pp. 561-569.

[19] J.C. Spohrer and H. Demirkan, Understanding service systems and operations: a closer look at the minority reports, Working paper, IBM \& Arizona State University, 2012.

[20]. T.W. Deacon, The symbolic species: the co-evolution of language and brain, WW Norton \& Company, New York NY, 1997.

[21] J.C. Spohrer and P.P. Maglio, Toward a science of service systems: value and symbols, In Handbook of Service Science, P.P. Maglio, C.A. Kieliszewski, J.C. Spohrer (eds.), Springer Publishing, New York City, NY, 2010.

[22] A. Newell, "The knowledge level”, Artificial Intelligence, vol. 18, 1982, pp. 87-127.

[23] C. Koliba, J.W. Meek and A. Zia, Governance networks in public administration and public policy, CRC Press: Taylor \& Francis Group, Boca Raton, FL, 2008.

[24] D. Friedman, Morals and markets: an evolutionary account of the modern world, Palgrave MacMillan, New York NY, 2008.

[25] J. Mollas-Gallart, A. Salter, P. Patel, A. Scott and X. Duran, Measuring third stream activities: final report to the Russell group of universities, Brighton: SPRU, Available at http://www2.lse.ac.uk/economicHistory/Research/
CCPN/pdf/russell_report_thirdStream.pdf.

[26] UU, Technology venture development, Annual report, University of Utah, 2011, Available at: URL http://content.yudu.com/Library/A1tbz4/.

[27] D. Clark, More pedagogic change in 10 years than last 1000 years, TEDxGlasgow, 2012. Available at URL:

http://www.youtube.com/watch?v=dEJ_ATgrnnY.

[28] C.M. Christensen, M.B. Horn, L. Caldera and L. Soares, Disrupting college: how disruptive innovation can deliver quality and affordability to postsecondary education, Center for American Progress, Innosight Institute, Available at http://www.americanprogress.org/issues/2011/02/pdf/disrupti ng_college.pdf.

[29] J. Spohrer, Services sciences, management, engineering: a next frontier in education, innovation and economic growth, Paper presented at: Services Marketing Workshop; Center for Services Leadership, Arizona State University, Tempe AZ, 2005.

[30] N. Donofrio, S. Calline and J. Spohrer, Collaborative innovation and service systems: implications for institutions and disciplines, In Holistic Engineering Education: Beyond Technology, Grasso D, Burkins MB. (eds.), Springer Publishing, New York City, NY, 2009.

[31] S. Barile, G. Franco, G. Nota and M. Saviano, "Structure and dynamics of a "T-shaped" knowledge: from individuals to cooperating communities of practice”, Service Science, vol. 4, no. 2, 2012, pp. 161-180.

[32] H. Demirkan and J.C. Spohrer, "Servitized enterprises for distributed collaborative commerce", International Journal of Service Science, Management, Engineering and Technology, vol. 1, no. 1, 2010, pp. 68-81.

[33] J.C. Spohrer and A. Giuiusa, Exploring the future of cities and universities: a tentative first step, In Proceedings of Workshop on Social Design: Contribution of Engineering to Social Resilience, May 12, System Innovation, University of Tokyo, Tokyo, Japan, 2012.

[34] J. Spohrer, P.P. Maglio, J. Bailey and D. Gruhl, "Steps toward a science of service systems", Computer, vol. 40, no. 1, 2007, pp. 71-77.

[35] J. Spohrer, S.L. Vargo, N. Casewell and P.P. Maglio, "The service system is the basic abstraction of service science", In the Proceedings of $41^{\text {st }}$ Hawaii International Conference on System Sciences, IEEE Press, New York, USA, 2008, pp. 1-10.

[36] National Science Foundation, Partnerships for innovation: building innovation capacity (PFI:BIC), Program Solicitation NSF14-610, National Science Foundation, Arlington, VA, 2014, Available at: http://www.nsf.gov/pubs/2014/nsf14610/nsf14610.pdf.

[37] A. Medina-Borja, "Editorial-Smart things as service providers: a call for convergence of disciplines to build a research agenda for the service systems of the future", Service Science, vol. 7, no. 1, 2015, pp. ii-v.

[38] J. Spohrer and H. Demirkan, Introduction to the smart service systems: analytics, cognition and innovation minitrack, In the proceedings of $48^{\text {th }}$ Hawaii International Conference on System Sciences, 5-8 January, 2015, Hawaii, USA, 2015.

[39] A. Medina-Borja, Special session with smarts workshop: NSF funding opportunities in smart service systems and other 
innovation program, 2016, Available at: http://www.smartcomp.org/nsf-session-on-smart-service-systems.html.

[40] F. Calza, M. Gaeta, V. Loia, F. Orcuiuoli, P. Piciocchi, L. Rarita, J. Spohrer and A. Tommasetti, "Fuzzy consensus model for governance in smart service systems", Procedia Manufacturing, vol. 3, 2015, pp. 3567-3574.

[41] P.P. Maglio, "Editorial column—smart service systems”, Service Science, vol. 6, no. 1, 2014, pp. i-ii.

[42] P.P. Maglio, "Editorial—smart service systems, humancentered service systems, and the mission of service science", Service Science, vol. 7, no. 2, 2015, pp. ii-iii.

[43] N. Dalal, "Wisdom computing: toward a framework for wisdom search in information systems", In the Proceedings of the Eighteenth Americas Conference on Information Systems, Seattle, Washington, August 9-12, 2012. Available at: http://aisel.aisnet.org/amcis2012/proceedings/

PerspectivesIS/14.

[44] JST, Wisdom computing - research and development for creative collaboration between humans and machines, 2014. Available at: http://www.jst.go.jp/crds/en/publications/ CRDS-FY2013-SP-07.html.

[45] K. Iwano and T. Motegi, "Wisdom computing: toward creative collaboration between humans and machines", Journal of Information Processing and Management, vol. 58, no. 7, 2015, 515-524 [Translation].

[46] K. Iwano, Wise computing: collaboration between people and machines, Panel discussion at AAAS Annual Meeting, San Jose, CA USA, 2015. Available at: https://aaas.confex.com/aaas/2015/webprogram/Session9386. html.
[47] J. Spohrer, From cognitive computing to wise (or wisdom) computing: a service science perspective, AAAS Annual Meeting, San Jose, CA USA. February 15, 2015. Available at: http://www.slideshare.net/spohrer/wisecomputing-20150215-v3

[48] J. Spohrer, C. Bassano, P. Piciocchi and M.A.K. Siddike, What makes a system smart? wise? Advances in The Human Side of Service Engineering, 27-31, 2017.

[49] E. Yudkowsky, Intelligence explosion microeconomics, Technical Report 2013-1, Machine Intelligence Research Institute, Berkeley, CA, 2013.

[50] I.I. Mitroff and H. A. Linstone, The unbounded mind: breaking the chains of traditional business thinking, Oxford University Press, New York NY, 1993.

[51] J. Spohrer, S. K. Kwan and R.P. Fisk, Marketing: a service science and arts perspective, Handbook of Service Marketing Research, Ed. Rust RT, Huang MH, Edward Elgar, New York NY, 2014, pp. 489-526.

[52] J.G. March, "Exploration and exploitation in organizational learning”, Organization Science, vol. 2, no. 1, 1991, pp. 71-87.

[53] A. Carr, Positive psychology: the science of happiness and human Strengths, Routledge, New York NY, 2011.

[54] M. Csikszentmihalyi, Flow: the psychology of optimal experience, Harper Perennial Modern Classics, 2008.

[55] R. Wright, Non-zero: the logic of human destiny, Vintage/Random House, New York NY, 2000.

[56] L.E. Freund and J. C. Spohrer, "The human side of service engineering”, Human Factors and Ergonomics in Manufacturing \& Service Industries, vol. 23, no. 1, 2013, pp. 2-10. 